\title{
A Risk-Hedging View to Refinery Capacity Investment in OPEC Countries
}

\author{
Hamed Ghoddusi ${ }^{a}$ and Franz Wirl ${ }^{b}$
}

\begin{abstract}
Should oil-rich members of OPEC invest in the oil refinery industry? This is a crucial energy policy question for such economies. We extend theoretical models for a vertical integration strategy within an oil-producing economy, based on a risk-hedging view. The first model highlights the trade-off between return and risk-reduction features of upstream/downstream sectors. The dynamic model demonstrates the volatility of the total budgetary revenue of each sector. Our theory-guided empirical analysis shows that though the average markup in the refining sector is significantly smaller than the profits in the upstream, downstream investment can provide some hedging value. In particular, the more stable and mean-reverting refining margins provide a partial revenue cushion when crude oil prices are low. We discuss the risk-hedging feature of the refinery industry when the crude oil market faces supply versus demand shocks.
\end{abstract}

Keywords: Refinery Industry, Hedging, Vertical Integration, Downstream Investment, Export Diversification

https://doi.org/10.5547/01956574.42.1.hgho

\section{INTRODUCTION}

Investing in the downstream sector to export refined products, as opposed to the export of crude oil, is an appealing and popular policy slogan in many oil-producing countries, including OPEC members. In 2010, OPEC's secretary-general predicted that "over the next decade, members were expected to invest around $\$ 40$ billion in refining capacity expansion." The ambitious idea to invest in downstream is, however, not new. An Iranian government stamp published in 1973 promotes a national dream for a full-vertical integration in the country's oil industry from well to the wheel. Also, a recent Bloomberg news item discusses UAE's ambitious plans to heavily invest in the downstream. ${ }^{2}$

The incentive for downstream investment is strong because it is tempting to export final products instead of the raw material. Anecdotal evidences ${ }^{3}$ suggest that the policy-makers in developing countries occasionally consider the value-added in the downstream sector (i.e., processed

1. http://www.downstreamtoday.com/news/article.aspx?a_id=23807 AspxAutoDetectCookieSupport=1.

2. https://www.bloomberg.com/news/articles/2018-05-10/as-saudis-pursue-aramco-ipo-abu-dhabi-hedges-to-stayrelevant.

3. https://www.weforum.org/agenda/2014/07/raw-material-value-wealth-ricardo-hausmann/.

a Corresponding author. Department of Finance, Orfalea College of Business, California Polytechnic State University, San Luis Obispo, CA 93407, United States. E-mail: hghoddus@calpoly.edu.

b Chair of Industry, Energy \& Environment, Faculty of Business, Economics and Statistics, University of Vienna.

The Energy Journal, Vol. 42, No. 1. Copyright (C) 2021 by the IAEE. All rights reserved. 
primary commodities) to be significantly larger than the upstream. ${ }^{4}$ The idea that a possible negative correlation between upstream and downstream profits can motivate vertical integration in the oil industry is first introduced by (McLean and Haigh, 1954). Opponents of the vertical integration policy believe that the value-added in the oil refinery sector is limited, and not much can be gained while exposing the country to substantial capital investment commitments, taking financial risks of the downstream business, and in some cases hiring expensive foreign labor.

To shed some light on the policy debate, we offer an analysis of the optimal downstream investing from a risk-hedging perspective. We build a static (single-period) model and a dynamic, forward-looking one. The first model highlights the trade-off between return and risk-reduction features of upstream/downstream sectors. The dynamic model characterizes the volatility of the total budgetary revenue of each sector. We take both models to the data to provide some quantitative insights in the case of crude oil refinery investment decisions. Our analysis is normative in natures; thus, we are not aiming at providing an explanation for the observed refinery capacities OPEC countries. Instead, our goal is to provide a framework to analyze such decisions critically.

To better motivate the relevance of the downstream investment opportunities in OPEC countries, Figure 1 shows the ratio of the domestic refining capacity to oil production capacity of countries. ${ }^{5}$ One observes a significant degree of heterogeneity among the major oil-producing nations. One also notes that due to a higher ratio of domestic consumption to production, non-OPEC oil producers (e.g., U.S. and China) tend to have a much larger ratio of downstream to upstream, compared to OPEC members. ${ }^{6}$

\section{Figure 1: Refining Capacity to Crude Oil Production Capacity. Data Source: IEA}

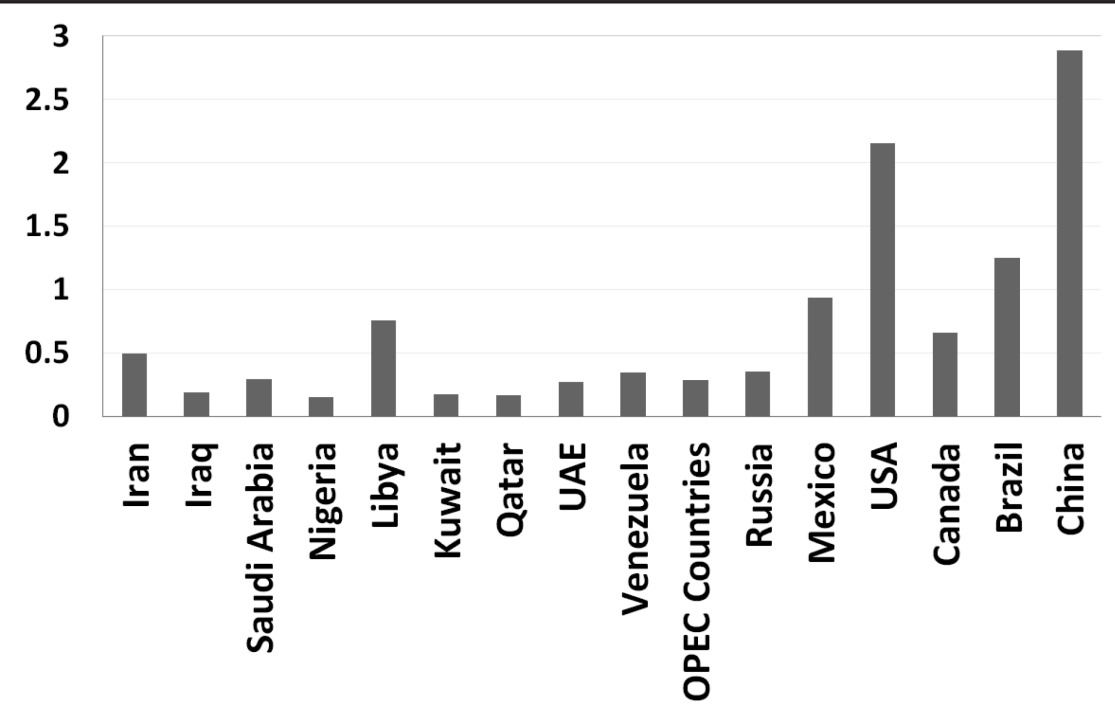

Volatile crude oil prices expose oil-exporting countries to major foreign exchange and government revenue risks, resulting in macroeconomic instabilities (especially in the presence of rigid

4. The perception of large untapped value in the oil refinery sector is likely to be induced by observations from other commodity markets.

5. A limitation of the table is that it only contains domestic refining capacity. Oil-producing countries may also own refineries overseas.

6. The refinery industry is complex and highly capital intensive. Financial constraints of oil-producing countries may have played a role in the observed weak vertical integration. 
exchange rate regimes) and causing the so-called resource curse effect (Van der Ploeg and Poelhekke, 2009). Commodity stabilization funds (Arrau and Claessens, 1992) and/or hedging through financial instruments (e.g. futures and options) are two commonly proposed methods to manage volatile oil prices (Devlin and Titman, 2004). Vertical integration along the supply chain is the third strategy, which we will discuss in more details. The low correlation of refinery markups and crude oil prices, as well as their different time-series dynamics, can potentially provide some degree of hedging to the current account of the oil-exporting country. Our theoretical models provide several empirical hypotheses for the relative value of the investment in the upstream and downstream sectors.

The optimal degree of vertical integration is a key input for the high-level energy and development discourse of oil-producing economies. Despite the obvious policy relevance and the potentially large resource commitment to investing in such industries, there is very little academic research on this topic (especially in recent years). To the best of our knowledge, our paper is one of the very few academic papers in the past two decades, specifically focusing on formal models and empirical results to analyze downstream investment in oil-rich countries. There are older papers (e.g. Al-Monsef, 1998; Al-Obaidan and Scully, 1993) which consider the problem of vertical integration for national oil companies. Also, Mabro (2006) provides a non-technical overview of the issue in a chapter. Finally, a small body of literature focuses on the energy policy choices of individual countries. For example, Krane (2015) discusses the incentives of Saudi Arabia for investing in downstream industries. We contribute to the literature by first extending the existing optimal portfolio models of the energy sector, and then offering an up-to-date empirical analysis of the problem.

In short, our contribution has two major dimensions. First, we extend current theoretical models to formally characterize hedging incentives for the downstream investment. Second, we show that the time-series dynamics of profits in the upstream and downstream sectors have different properties. More precisely, due to the mean-reverting nature of cash-flows in the refinery sector, the present value of the downstream revenues is significantly less volatile than of the upstream.

\section{LITERATURE REVIEW}

Our work is built on insights from research in the natural resource and energy economics as well as the industrial organization (IO) literature. In a broad sense, our work is related to the large and mature literature on the resource curse (Frankel, 2010) and the political economy of oil-producing countries (Beland and Tiagi, 2009; Ross, 1999). The resource curse literature not only highlights the role of institutions (e.g., Cabrales and Hauk, 2011) but also emphasizes that the way natural resource revenues are spent plays a critical role. Commodity price volatility has also been identified as a major source of the resource curse in resource-rich countries (Van der Ploeg and Poelhekke, 2009). Volatile terms of trade can suppress productivity growth, even in the presence of large capital accumulations.

Investment in downstream could be a potential remedy for the resource curse if it helps oil-rich countries alleviate some of the negative features of exporting crude oil, such as the volatility in the export revenues. Merener and Steglich (2018) consider the role of price correlation to gauge the price performance of diversified economies and conclude that diversified commodity-producing countries face a significantly lower risk than specialized producers. Borensztein et al. (2013) quantify the welfare gains of hedging against the commodity price risk for commodity-exporting countries and highlight the first-order effect of reducing precautionary saving. Van der Ploeg and Venables (2011) discuss policy options for spending resource revenues. Export diversification is a key suggestion to reduce the magnitude of the resource curse. Herzer and Nowak-Lehnmann D (2006) and Bertinelli 
et al. (2009), among others, empirically examine the export diversification structure of resource-rich countries and conclude that considerable welfare can be gained if these countries move toward an optimal export portfolio. Alwang and Siegel (1994) evaluate the usefulness of portfolio models in advising export diversification policies for resource-rich countries. Labys and Lord (1990) use portfolio optimization techniques to determine the optimal export diversification strategy for Latin American countries. Massol and Banal-Estañol (2014) apply an optimization model to identify the optimal downstream investment for gas-rich countries. Cherif and Hasanov (2013) model the consumption, saving, and investment decisions of oil-exporting countries and show that a sizable precautionary saving is optimal for such economies. If the downstream investment can reduce the volatility of export revenues, a lower level of precautionary saving might be optimal. Thus, precautionary saving and downstream investment can be considered as potentially substitute policies.

A variety of reasons (e.g., transaction costs, property rights, agency issues) are offered for vertical integration and have been extensively discussed in the industrial organization (IO) literature (see Carlton, 1979; Lieberman, 1991; and Joskow, 2012). Suzuki et al. (2011) provide an interesting rationale for partial vertical integration when small suppliers have a superior ability to absorb demand shocks. Also, Aïd et al. (2011) and Léautier and Rochet (2014) discuss the risk-reduction incentives of vertical integration. However, some insights from that literature are not directly applicable to the oil industry. From the perspective of the refinery industry, crude oil has no economic substitute as the major input. Thus, the downstream of the oil industry is not making a strategic choice of input, and there is little room for the upstream monopolist to influence the downstream decisions. This eliminates strategic considerations that are typical in the IO literature.

Levin (1981) and Barrera-Rey (1995) study the effect of vertical integration on the performance of oil companies and find no impact on the profitability but a small effect on risk reduction. Norton (1993) shows that vertical integration reduces systematic risks for refinery companies. The optimal hedging strategy for refiners has been studied by several papers (e.g. Sykuta, 1996; Sukcharoen and Leatham, 2017). Alexander et al. (2013) criticize the merits of the standard mean-variance optimization methods for determining the optimal hedging policy. Our paper differs from this literature by focusing on the profitability of the upstream rather than the profitability of the refinery. Moreover, we address the problem from a policy-making perspective.

\section{THEORETICAL ANALYSIS}

We build two stylized theoretical models (one static and one dynamic) to better identify the relationship between various underlying factors and the optimal degree of vertical integration.

Key notations are introduced and summarized in Table 9 of Appendix A. Our first model borrows insights from the portfolio theory literature; however, since it is applied to physical (as opposed to traded) assets, the results for financial portfolios are not directly applicable. Following other papers in the literature (e.g., Laughton et al., 2000), we modify and extend the basic portfolio optimization models to account for the special features of the oil and refinery industries. Using our extended models, we derive some implications that are evaluated against empirical findings.

\subsection{Basics Assumptions and Components of Model}

The oil-producing economy is endowed with a large reserve of natural resources (crude oil) sold in international markets at an exogenously specified random price $P$. The constant cost of extracting a barrel of oil is $\theta$, resulting in $P_{t}-\theta$ unit of net revenue from each barrel of crude oil. 


\subsubsection{Stochastic Processes}

The price of crude oil and the level of crack spreads (i.e refining margins) are both random variables defined by the following equations:

$$
\left\{\begin{array}{l}
P=\bar{P}+\varepsilon_{P} \\
C=\bar{C}+\varepsilon_{C}
\end{array}\right.
$$

where $\bar{P}$ and $\bar{C}$ represent the base level of crude oil price and crack spreads and $\varepsilon_{P}$, and $\varepsilon_{C}$ are normally distributed, mean-zero shocks to the baseline levels with variances $\sigma_{U}$ and $\sigma_{D}$, respectively. The covariance of shocks to the two sectors is denoted by $\sigma_{U, D}$ is.

\subsubsection{Investment Costs}

The country faces a total investment budget constraint of $\bar{I}$, which can be allocated to build upstream and downstream capacities. The cost of $K_{U}$ and $K_{D}=\omega K_{U}$ units of upstream and downstream capacity are given by two functions, $I_{1}\left(K_{U}\right)$ and $I_{2}\left(K_{D}\right)$, respectively. The simplified investment budget constraint is capturing frictions such as the limited pledgeability (i.e., the collateral value) of a country's energy sector assets, the capacity of the domestic financial system, and the risk diversification motives of international lenders. Due to these frictions, the country can only raise a total of $\bar{I}$ units of capital. The budget constraint imposes the standard condition of $I_{1}\left(K_{U}\right)+I_{2}\left(K_{D}\right) \leqslant \bar{I}$.

The investment cost functions are assumed to be continuous, increasing, and convex in $K_{U, D}$ (see Ghoddusi et al. (2017) for a detailed discussion of the implications). Following the standard merit-order assumption of natural resource economics, the convexity of the investment cost function captures the decreasing return to scale or the increasing cost of exploiting new reserves (Holland, 2003). ${ }^{7}$ The average capital cost per barrel in the upstream and downstream sectors are approximately $10 \$ / \mathrm{b}$ and $2.85 \$ / \mathrm{b}$, respectively. Thus, it is plausible to assume that building one unit of upstream is more expensive than a unit of refinery capacity, $K_{U}>K_{D}$. For a more detailed discussion, see Appendix E.

\subsubsection{Investment Policy}

The oil-rich country decides on the optimal degree of vertical integration, $\omega$, defined as $\omega=\frac{K_{D}}{K_{U}}$, as the main control variable. The country chooses $\omega$ once and forever. Since restructuring is very difficult in the case of physical assets, we assume that the government makes a one-shot perpetual decision based on the expected behavior of the upstream and downstream revenues, i.e., a one-period optimization problem.

7. The merit-order model of resource extraction and production suggests that the country first starts extracting from the most efficient reserve and then moves to less efficient ones. This can be translated into the increasing marginal cost of building an extra unit of capacity, which is captured through the convex form of investment functions. 


\subsection{Static Model}

\subsubsection{Objective Function}

The objective of the social planer is to maximize the expected utility through choosing an optimal level of vertical integration $\left(0 \leqslant \omega=\frac{K_{D}}{K_{U}}\right): 8$

$$
\left\{\begin{array}{l}
\max _{K_{U}, K_{D}} Z=\mathbb{E}\left[U\left(K_{U}, K_{D}\right)\right] \\
\text { s.t. } \\
I_{1}\left(K_{D}\right)+I_{2}\left(K_{U}\right)=\bar{I}
\end{array}\right.
$$

Proposition 3.1 Under a mean-variance preference with the parameter of risk-aversion $\gamma,{ }^{9}$ the optimal level of investment in the upstream and downstream is given by the following condition:

$$
\frac{\bar{P}-\theta-2 \gamma\left[K_{U} \sigma_{U}^{2}+K_{D} \sigma_{U, D}\right]}{\bar{C}-2 \gamma\left[K_{D} \sigma_{D}^{2}+K_{U} \sigma_{U, D}\right]}=\frac{I_{1}^{\prime}\left(K_{U}\right)}{I_{2}^{\prime}\left(K_{D}\right)}
$$

\section{Proof See Appendix B}

Following the standard results of the optimal portfolio theory (see, e.g., Varian and Varian (1992), Chapter 20), the solution of Equation 3 (the model with a risk-averse social planner) will always result in an interior solution, with positive investment in both sectors.

\subsection{Dynamic Model: Serial Correlation in Shock}

One key extension of the previous model is to consider the case when the planner is concerned with the expected present value of future revenues over a time period (as opposed to a single period only). In this case, the serial correlation processes should be taken into account, and a dynamic model needs to be presented.

With the possibility of inter-temporal transfers (i.e., borrowing and saving), the government spending of the OPEC country is bounded by the present value of its total lifetime budget. For simplicity, assume there are no other government revenue sources such as domestic taxes. ${ }^{10}$ The present value of all government spending cannot be larger than the present value (PV) of revenues from the upstream and downstream sectors.

We show that the expected PVs of revenues from the upstream and downstream sectors are themselves random variables. The annual export revenue from one year to another year may change as a function of the latest realization of volatile spot prices and refining margins; consequently, the expectations of future revenues and the expected present value of revenues also change.

8. One key difference between solving the optimal portfolio problem for physical and financial assets is that, unlike financial portfolios, the investment on physical assets can not short positions.

9. The mean-variance preference is defined as $U(X)=\mathbb{E}(X)-\frac{\gamma}{2} \operatorname{Var}(X)$.

10. The share of oil-related revenues in the government budget of OPEC countries is very high. 
To shed a light on this matter, we derive explicit solutions for the present value of revenues from those sectors and compare their time dynamics and volatility. The general problem can be formulated as:

$$
X=\mathbb{E}\left[\int_{t}^{t+T} x_{s} e^{-r(s-t)} d s\right]
$$

where $x_{s}$ is a stream of instantaneous random revenues, and $X$ is the expected present value of revenues over the next $T$ periods. To make the analysis of the closed-form solutions more elegant, we let $T \rightarrow \infty$. Note that if discount rates are sufficiently large, the present values of cash-flows in the far future become small; thus, extending the horizon to infinity will not have a major effect on the solution.

\subsubsection{Stochastic Processes}

A critical component of our analysis is the time-series behavior of crude oil price and crack spread processes. The more common view in the literature is the price of crude oil is close to a unitroot process (i.e., non-stationary); whereas, crack spreads follow a mean-reverting process Smyth, 2008). ${ }^{11}$ This view will be re-confirmed in Table 1 of the next section. The stochastic differential equations governing the Geometric Brownian Motion (GBM) process for the crude oil price and the mean-reverting crack-spreads is given by:

$$
\left\{\begin{array}{l}
\frac{d P}{P}=\mu d t+\sigma d W \\
d C=(\bar{C}-C) \mu d t+\sigma_{C} d W_{C}
\end{array}\right.
$$

Proposition 3.2 the expected present value of all future oil revenues will be given by:

$$
V_{t}=\mathbb{E}_{t} \int_{t}^{\infty}\left[P_{s}-\theta\right] e^{-r(s-t)} d s=\frac{P_{t}}{r-\mu}-\frac{\theta}{r}
$$

Proof The result can be easily derived following standard steps presented in [19].

Equation 6 states that the expected present value of oil revenue is a function of the spot price of oil. Therefore, the relative volatility of the two variables can be derived.

Proposition 3.3 Absent extraction costs (i.e., assuming $\theta=0$ ), the ratio of the volatility of the total oil revenue to the volatility of crude oil prices, $\xi_{\text {Oil Revenue }}$, is equal to one.

$$
\xi_{\text {Oil Revenue }}=\frac{\operatorname{volatility}(V)}{\operatorname{volatility}(P)}=1
$$

Proof The result is an immediate implication of Equation 6.

Proposition 3.3 suggests that the volatility of the upstream revenue process is as large as the volatility of the spot prices of crude oil. In reality, the marginal extraction cost for the majority of OPEC members is smaller than $5-10 \$ / b$. Thus, $\theta=0$ is a plausible approximation. ${ }^{12}$

11. As an example of papers challenging the unit-root property of the crude oil price, see Lawal et al. (2018).

12. https://knoema.com/vhzbeig/oil-statistics-production-costs-breakeven-price 
Proposition 3.4 The present value of the downstream revenues is given by:

$$
Y_{t}=\int_{t}^{\infty} \mathbb{E}_{t}\left(C_{s}\right) e^{-r(s-t)} d s=\underbrace{\frac{\bar{C}}{r}}_{\text {Perpetual value of long-run equilibrium price }}+\underbrace{\frac{\left(C_{t}-\bar{C}\right)}{r+\mu_{C}}}_{\text {Correction for current deviation }}
$$

\section{Proof See Appendix C}

Proposition 3.4 suggests that the volatility of the revenue process in the downstream is always smaller than the volatility of spot refining margins. On the other hand, the volatility of the revenue process in the upstream sector is as volatile as the underlying spot prices.

\subsection{Implications of the Theoretical Analysis}

Using the two theoretical models, we are able to derive the following implications.

Implication 1 The intensity of downstream investment will be higher when the covariance of shocks to upstream and downstream profits is smaller.

Implication 2 The incentive to invest in the downstream is larger if the volatility of the upstream sector is large, and if the volatility of downstream is small.

Implication 3 If crude oil prices are high, the relative attractiveness of the refinery sector is lower.

Implication 4 It is expected that high-cost countries have a higher incentive to invest in the downstream sector. The higher the extraction cost of crude oil, the higher the relative importance of the crack-spreads.

Implication 5 The benefit of hedging is higher for a risk-averse agent. If the agent is completely risk-neutral, the hedging benefits of the downstream investment disappear, and the only relevant factor would be the excess return in this sector.

Implication 6 The source of crude oil price fluctuations matters for the optimal degree of downstream investment. If the crude oil price is mainly driven by demand shocks, the incentive to invest in downstream is smaller.

Proof To see how the six implications follow the results of the theoretical models, please refer to Appendix D.

\section{EMPIRICAL ANALYSIS}

\subsection{Data}

We download monthly data on wholesale spot prices of Brent crude oil, NY gasoline, and NY heating oil from the Energy Information Administration (EIA). The dataset covers 1987/052019/04 (400 monthly observations) on spot prices of fuels. Capacity utilization data comes from BP's Energy Outlook (2017) report. Refining capacity, production, domestic consumption, and export data are all from EIA. All price variables are real (converted to $2015 \$$ values). Unless otherwise mentioned, the reader should assume that the presented variables are in real terms.

The price of crude oil basket exported by the member states of OPEC (e.g., OPEC basket, Iran light and heavy, and Dubai) is only available since 2003; whereas, Brent data is available since 
1987. To have a larger sample, we choose to work with Brent crude oil and U.S. NY Harbor refined products prices as proxies for characterizing the performance of a representative downstream industry. Using Brent as a proxy is an innocuous assumption that increases the power of statistical tests without inducing a bias. As a robustness test, we compared the behavior of Brent and OPEC basket over the 2003-2018 period and found a negligible difference between the two price series throughout the 2003-2018 sample. Thus, the analysis using Brent can be confidently considered representative for OPEC countries too.

\subsection{Crude Oil Prices and Refining Margins}

Figure 2 shows the time-series of real prices of crude oil as well as the real crack spread. While crude oil prices take a wide range of values (and also seem to behave close to a random walk), crack spreads show a low-volatility and mean-reverting behavior staying in a more limited range. ${ }^{13}$ We will report the detailed statistical analysis of these patterns below.

Figure 2: Crude Oil Prices versus the Refinery Profitably Measure (both in 2015\$).

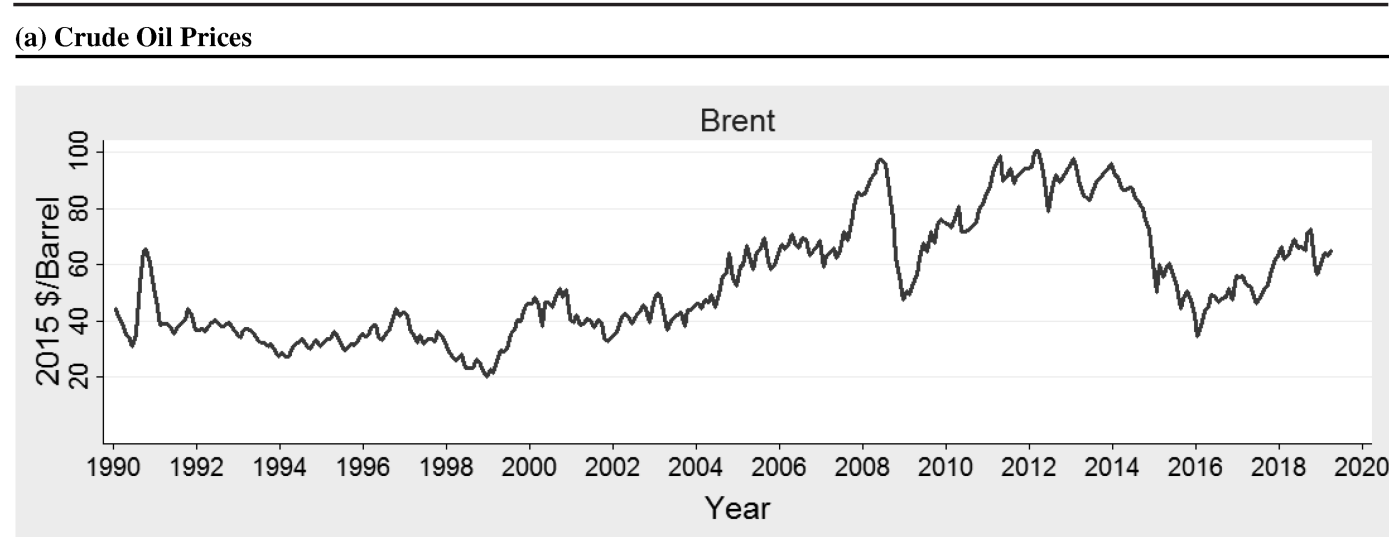

(b) The Refinery Profitably Measure

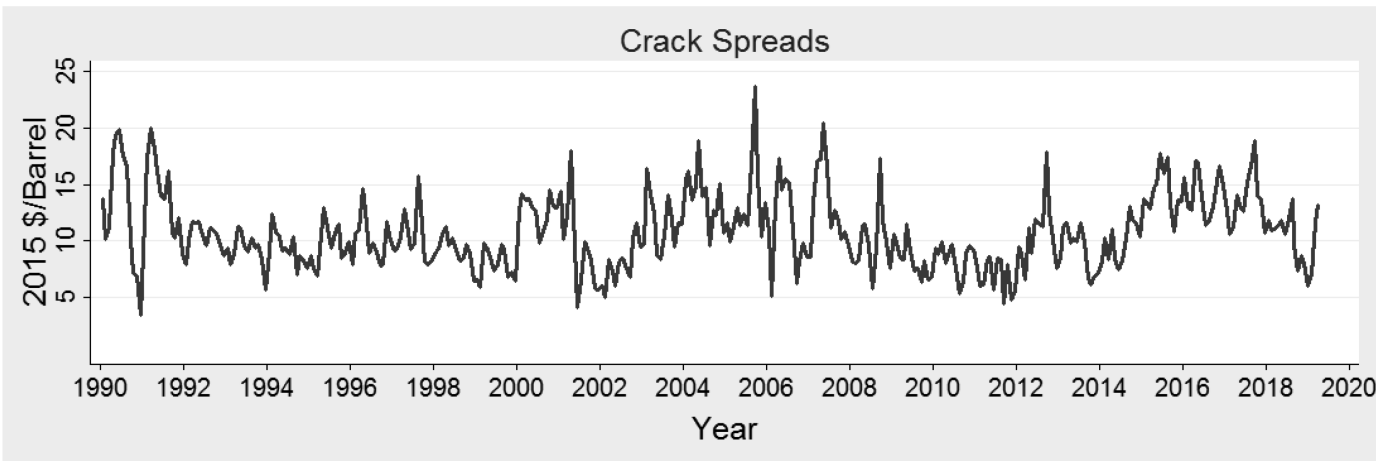

Table 1 provides basic descriptive statistics of crude oil, major refined products, and also various measures of the spread between refined products and crude oil (to be used as proxies for the

13. A mean-reverting process can also take a wide range of values if the volatility parameter is sufficiently large. In the case of crack spreads, the volatility is small. 
profit margin of the downstream sector). It is well-known that the crude oil price series are non-stationary, and the typical descriptive statistics (e.g., variance) for a non-stationary process are not well defined. We report these values only to provide a comparison between the behavior of crude oil prices and refining margins within the sample of 1990-2019. Therefore, the statistics should not be interpreted as the moments of the data-generating process (which do not exist) but should be read as sample statistics.

Our choice of the refining margin is motivated by the famous 1-2-3 crack spread, defined as the difference of three units of Brent crude oil, two units of NY harbor gasoline, and one unit of heating oil. One can debate the choice of the weights of the crack spreads (e.g., using a 2-3-5 crack spread) or even including the value of other refined products in the measure. However, the overall behavioral patterns reported in this section will not change.

Table 1: Descriptive Statistics of Original Prices

\begin{tabular}{lccccc}
\hline Price & Mean & Median & Standard Deviation & Skewness & Kurtosis \\
\hline Brent & 54.21 & 48.43 & 20.72 & 0.59 & 2.21 \\
NY Gasoline & 64.99 & 61.87 & 19.94 & 0.36 & 2.05 \\
Heating Oil & 65.03 & 60.46 & 22.52 & 0.49 & 2.18 \\
Jet Fuel & 65.71 & 59.70 & 23.34 & 0.49 & 2.09 \\
Gasoline - Brent & 10.78 & 10.34 & 4.63 & 0.58 & 3.67 \\
Heating Oil - Brent & 10.82 & 10.48 & 4.15 & 0.82 & 3.73 \\
Jet Fuel - Brent & 11.39 & 10.37 & 4.74 & 0.70 & 10.01 \\
Crack Spread & 10.80 & 10.30 & 3.25 & 3.52 \\
\hline
\end{tabular}

\subsection{Results Empirical Analysis}

This section provides a few empirical results regarding the relationship between crude oil prices and downstream metrics of profitability.

\subsubsection{Average Level of Value-Added}

Given its competitive industrial organization, the refinery industry produces a normal economic profit consistent with other competitive industry performances. ${ }^{14}$ To provide a better understanding of the profit margins in this industry, we plot the histogram of monthly net refining margins for a representative refinery of North America in Figure 3. The net refining margin is obtained after subtracting refining costs from crack spreads. The operational expenses of the refining vary between $\$ 4-\$ 7$ depending on the region and the production technology. ${ }^{15}$ We choose $5 \$ / b$ as the baseline refining cost. ${ }^{16}$

From the numbers displayed on the histogram, one can infer a small range (between $0-\$ 10$ ) for the typical margin of value-added in the downstream sector. Industry reports on refining margins (e.g., BP Statistical Review of World Energy ${ }^{17}$ ) also provide very similar results that support our calculations; average refining margins in different regions are typically around $5 \$ / \mathrm{b}$. The average refining margin can be contrasted to the upstream revenue: considering a recent historical average $55 \$ / \mathrm{b}$ crude oil price and an average $5 \$ / \mathrm{b}-10 \$ / \mathrm{b}$ production costs for OPEC countries, they make a net $45 \$ / b-50 \$ / b$ revenue from the upstream sector. Thus, the net margin of upstream is between 5 to 10 times larger than the net refining margin.

14. Normal profit refers to the case where all production factors receive their equilibrium market rate. In other words, there is no rent accruing to the owners of the capital assets.

15. https://www.iea.org/media/omrreports/Refining_Margin_Supplement_OMRAUG_12SEP2012.pdf

16. https://iea-etsap.org/E-TechDS/PDF/P04_Oil\%20Ref_KV_Apr2014_GSOK.pdf

17. https://www.bp.com/en/global/corporate/energy-economics/statistical-review-of-world-energy/oil/refining.html 
Figure 3: Histogram of Net Profit Margins (2015\$).

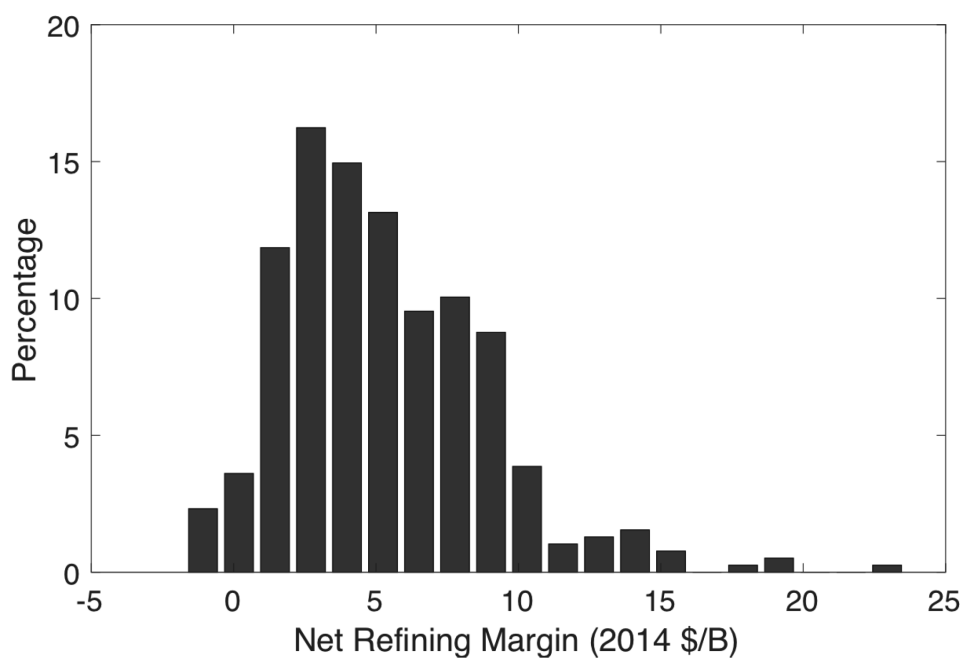

Notes: We subtract a $5 \$ / \mathrm{b}$ refining cost from crack spreads to produce net refining margins. Number on bars show the percentage of observations.

\subsubsection{Relationship between Crude Oil and Crack Spreads}

Figure 4 shows the scatter plot of the crack spreads against the change and level of crude oil prices, using monthly data.

Figure 4: Crack Spreads versus Crude Oil Prices

(a) Monthly "Change" Observations

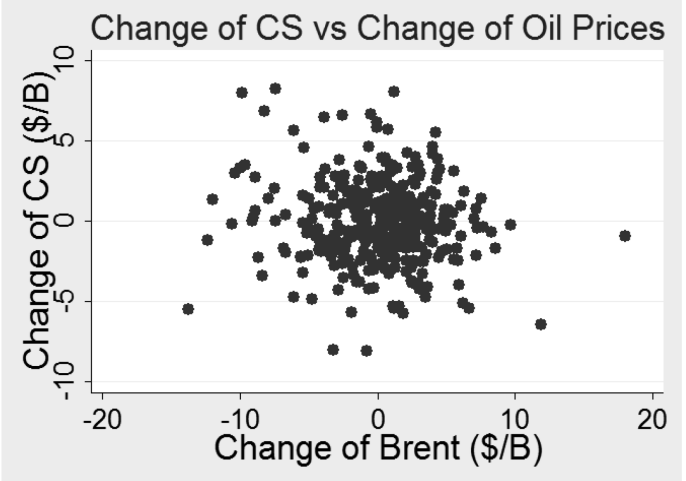

(b) Monthly "Level" Observations

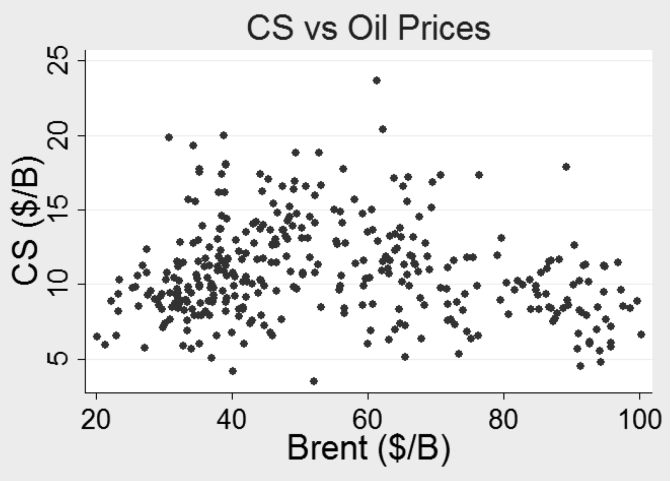

The visual inspection suggests no relationship between the changes in crack spread and crude oil prices. To formally test the relationship, we run the following simple regressions on the first-difference of the two variables. ${ }^{18}$

$$
\Delta C_{t}=\beta_{1}+\beta_{2} \Delta P_{C t}+\varepsilon_{t}
$$

18. Note that the regression is not balanced in terms of the degree of integration. While the crude oil price process becomes $\mathrm{I}(0)$ only after the first difference, the original crack spreads process was $\mathrm{I}(0)$, and we have taken the first difference of an $\mathrm{I}(0)$ process. However, this is not a major issue because both series have become stationary. 
Results reported in Table 2 support the visual observation that the relationship between changes (i.e., first difference) of the two variables is statistically insignificant. The zero correlation of changes in crude oil prices and refinery profits, justify using the refinery industry as a hedging mechanism for oil-producing countries. Note that the refining process (aka cracking) is energy-intensive, and higher natural gas prices will reduce the real level of crack spreads. We assume a constant level for processing costs. If one takes into account the higher processing costs during high crude oil prices, the negative relationship between crude oil prices and net crack spreads will become even larger and provides stronger support for the hedging argument.

Table 2: Relationship between crack spreads and crude oil prices

\begin{tabular}{lc}
\hline Variables & $\Delta C_{t}$ \\
\hline$\Delta P_{C t}$ & $-0.0637 *$ \\
& $(0.0343)$ \\
Constant & 0.00224 \\
& $(0.136)$ \\
\hline Observations & 351 \\
R-squared & 0.0098 \\
\hline *: indicates 10\% significance level. \\
Standard errors are in parentheses.
\end{tabular}

To further investigate the connection between crude oil and crack spreads, we divide the full sample to six five-year sub-samples and estimate the correlation within each sub-sample. Figure 5 shows time-varying correlation of the two series. We observe that in the late 1980s, the correlation was negative; however, since then, the correlation is not statistically different from zero. The recent patterns of zero correlation are not ideal for hedging because a negative correlation could provide a more effective hedge; however, even a zero correlation supports hedging because the combination of two assets with zero correlation will significantly reduce the overall risk of a revenue portfolio (see Implication 2).

Figure 5: Time-Varying Correlation of Crude Oil Prices and Crack Spreads.

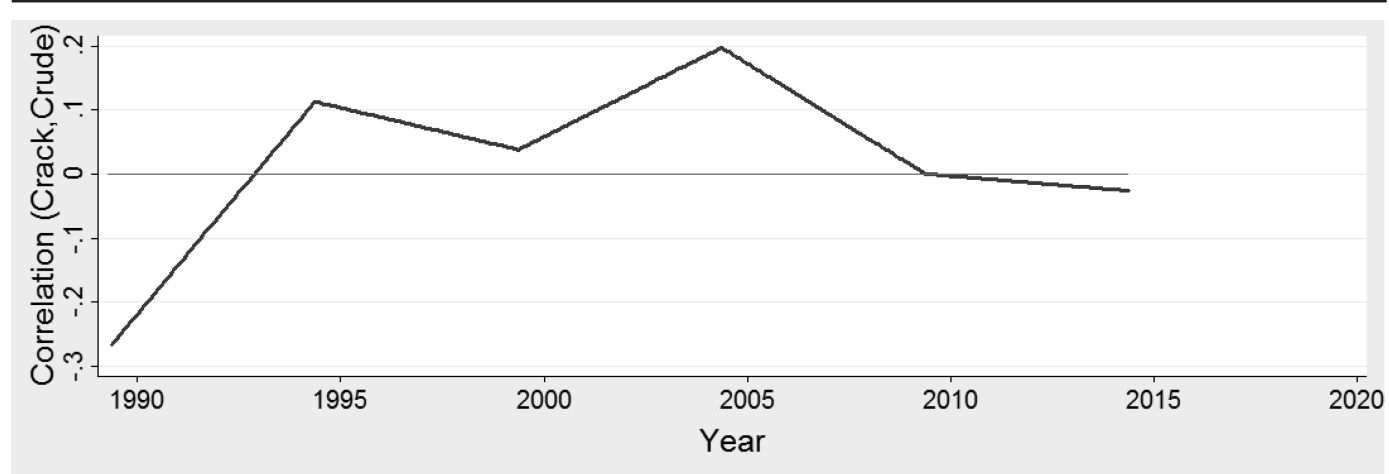

Note: Each bar shows the estimated correlation for a 60 -month window starting by that year.

A negative correlation in the 1980s is consistent with a supply-driven market in our theoretical analysis. However, the more demand-driven market in recent years has changed the correlation to zero. The demand volatility is combined with a new supply-side shock (the shale revolution) in recent years; the net effect causes the correlation to become near zero. 
Table 3: Correlation of First-Difference of Crude Oil Prices and Crack Spreads

\begin{tabular}{lcc}
\hline Period & Number of Observations & Correlation \\
\hline $1989 / 05-1994 / 04$ & 60 & $-0.2667^{* *}$ \\
$1994 / 05-1999 / 04$ & 60 & 0.1132 \\
$1999 / 05-2004 / 04$ & 60 & 0.0382 \\
$2004 / 05-2009 / 04$ & 60 & 0.1975 \\
$2009 / 05-2014 / 04$ & 60 & 0.0003 \\
$2014 / 05-2019 / 04$ & 60 & -0.0259 \\
\hline
\end{tabular}

**: indicates $5 \%$ significance level.

\subsubsection{Mean-Reversion in Series}

The different time-series behavior of crude oil prices and refinery markups, shown in Figure 2, is an important feature of the data, which has been extensively studied in the literature (Choi and Hammoudeh, 2009). The results of multiple unit-root tests reported in Table 4, almost unanimously, support the view that prices (crude oil and refined products) contain unit-roots and are non-stationary; whereas, measures of spread are stationary. ${ }^{19}$

We also allow structural breaks in the unit-root behavior of the time-series and test the existence of such breaks. Figures 6 and 7 show the identified structural breaks in the price and refining margins series, respectively.

To check if the existence of the structural break affects our conclusions regarding the existence of unit-root in the series, in Table 5 and Table 6 we report unit-root tests for sub-samples before and after the break. We note that the conclusions are robust, and the behavior of the sub-samples before and after the break are mainly similar to each other.

\subsection{Quantitative Model: Calibration}

In order to provide better intuition, we calibrate the stochastic processes for the price of crude oil and refining margins using historical data and standard maximum likelihood (ML) techniques. Table 7 summarizes key parameters. The half-life of the refinery margin process is equal to $\frac{\log (2)}{0.28} \approx 2.5$ months. Assuming a monthly discount rate of $0.4 \%$ (apprx $5 \%$ p.a), we get $\frac{\mu}{r} \bar{C}=2.59$ and $\sigma_{Y}=\frac{\sigma_{C}}{\mu+r}=\frac{2.52}{0.4+0.28}=3.70$.

The relative volatility of upstream and downstream revenues are calculated by estimating $\frac{\operatorname{std}(V)}{\text { mean }(V)}$ for each sector. As expected, the relative volatility of the downstream revenue is one order of magnitude smaller than the upstream revenue. Thus, the downstream sector provides a much more stable long-term revenue (in a total cash-flow sense).

Hedging Issue Our results reveal a key challenge to using the downstream sector for hedging purposes: the social-planner is willing to combine the two sectors to benefit from the larger level of the present value in the upstream and the lower volatility of present value in the downstream. However, this implies hedging a unit-root process (i.e., the value of the oil revenues) by using a mean-reverting process (i.e., the downstream revenue).

19. OPEC has some power to determine the time-series behavior of crude oil. If OPEC responds aggressively to demand shocks, the price of crude oil will also be close to mean-reverting. 


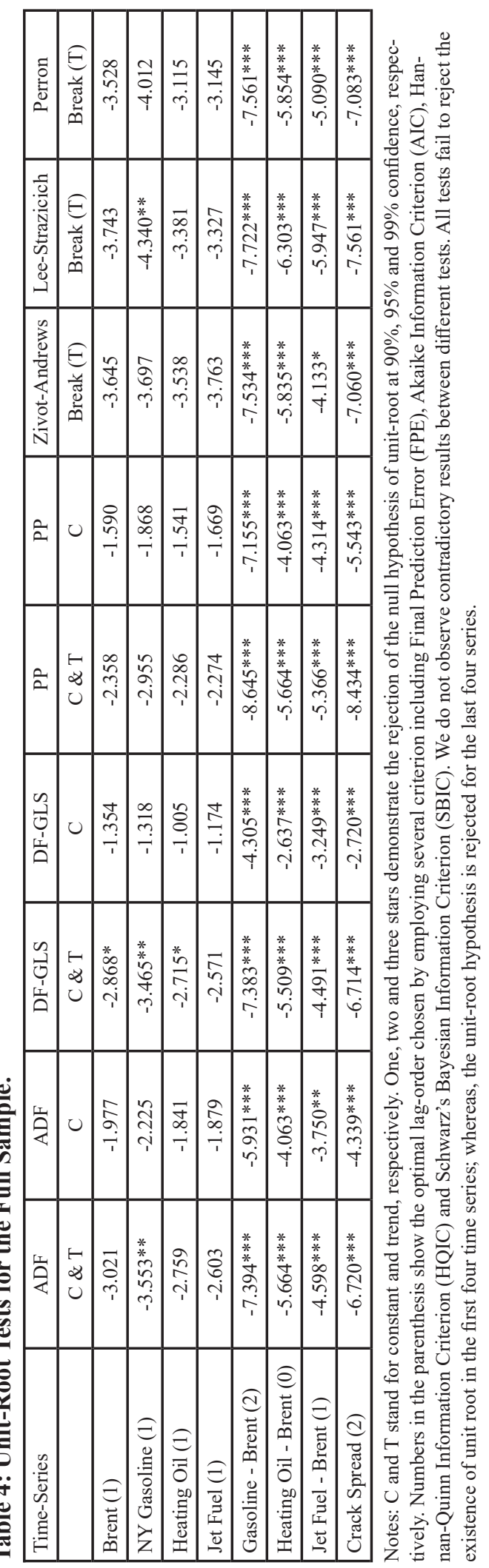




\section{Figure 6: Structural Break-Point for Oil Products}
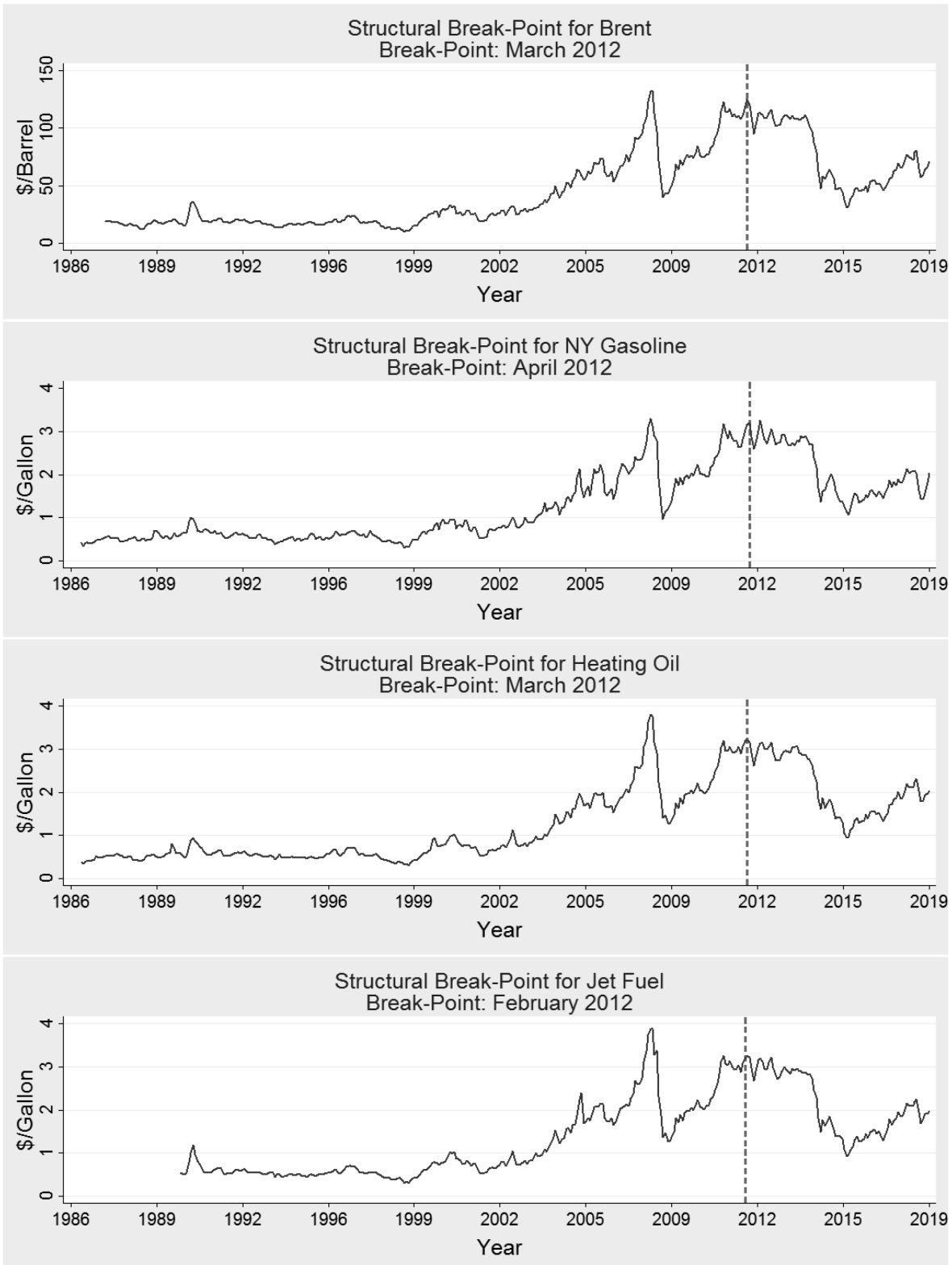

The Vertical Dashed Line is the Structural Break-Point.

In theory, a unit-root process has an unbounded variance and cannot be hedged by a finite variance mean-reverting process. However, if the horizon of the problem is assumed to be finite (e.g., five years), then one can take a pragmatic approach to blend unit-root and mean-reverting assets to reduce the volatility of the overall revenue process. ${ }^{20}$

20. If the moments of the process are near-stationary within the sample, one can use a long sample (e.g., 30 years) to estimate the parameters and then simulate the model for a different time-horizon to estimate the optimal hedge ratio. 
Figure 7: Structural Break-Point for Difference of Oil Products
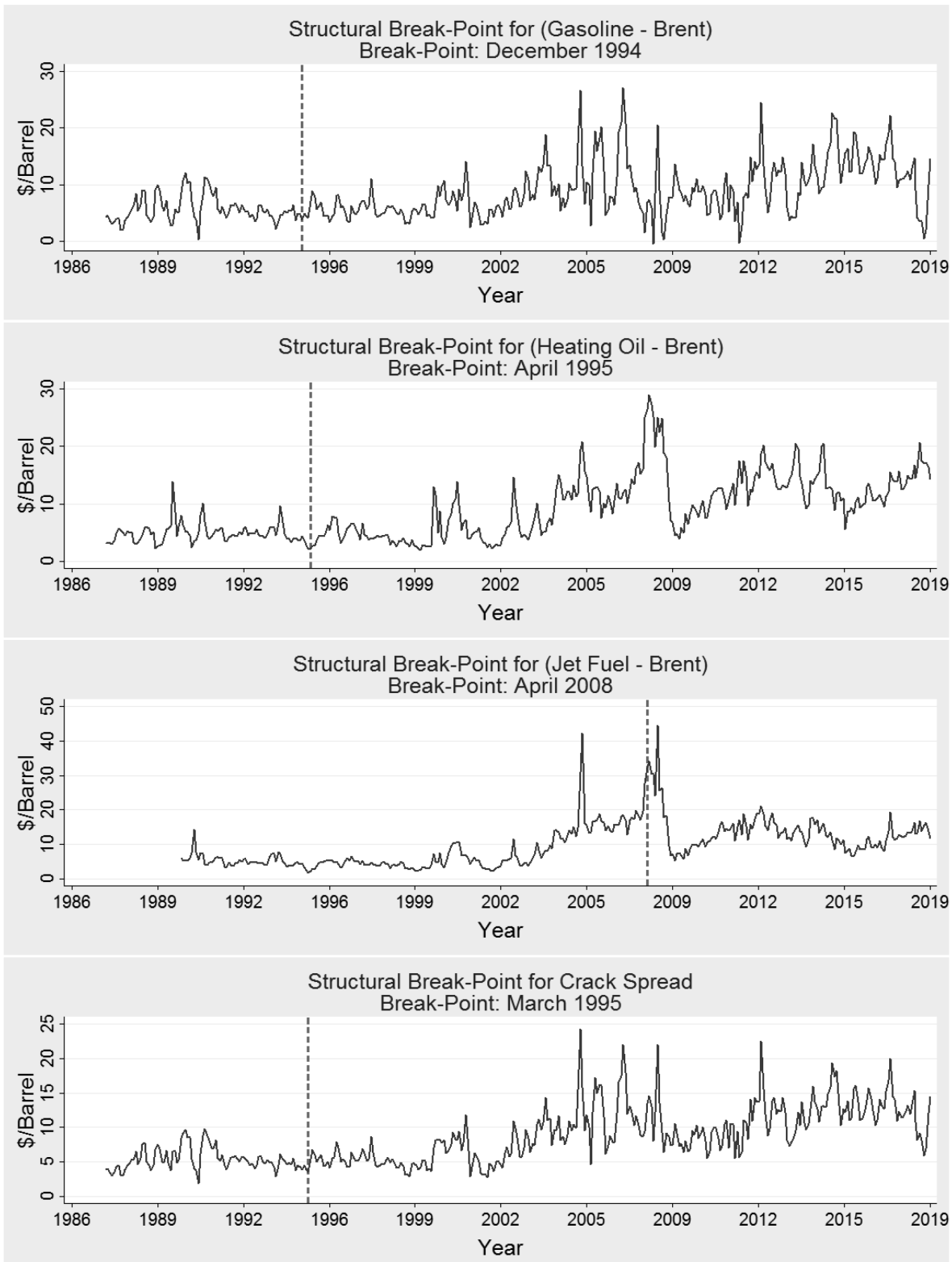

The Vertical Dashed Line is the Structural Break-Point.

\subsection{Summary of Empirical Findings}

Empirical Result 1 The correlation between changes in crude oil and refining margins in recent years is near zero. The correlation in the 80 s was negative but has converged to zero in recent periods. Consistent with the Theoretical Implication 1, this fact supports downstream investments motivated by risk-hedging considerations.

Empirical Result 2 For OPEC countries, the expected net profit in the upstream is significantly larger than the downstream sector. In line with the theoretical implication 4, this fact may partially 
Table 5: Unit-Root Tests for Before Break-Point.

\begin{tabular}{|l|l|l|c|c|c|c|c|}
\hline Time-Series & Break-Point & ADF & ADF & DF-GLS & DF-GLS & PP & PP \\
\hline & & C \& T & C & C \& T & C & C \& T & C \\
\hline Brent (1) & Mar 2012 & -2.674 & -0.721 & -2.218 & -0.227 & -1.966 & -0.150 \\
\hline NY Gasoline (1) & Apr 2012 & -2.968 & -1.052 & $-2.707 *$ & -0.321 & -2.442 & -0.606 \\
\hline Heating Oil (1) & Mar 2012 & -2.363 & -0.686 & -2.189 & 0.037 & -1.841 & -0.207 \\
\hline Jet Fuel (1) & Feb 2012 & -2.671 & -0.889 & $-2.279 *$ & -0.320 & -2.381 & -0.658 \\
\hline Gasoline - Brent (2) & Dec 1994 & $-4.330^{* * *}$ & $-4.336^{* * *}$ & $-4.123^{* * *}$ & $-3.766^{* * *}$ & $-4.038^{* *}$ & $-4.052^{* * *}$ \\
\hline Heating Oil - Brent (0) & Apr 1995 & $-4.728^{* * *}$ & $-4.771^{* * *}$ & $-4.902^{* * *}$ & $-4.024^{* * *}$ & $-4.728^{* * *}$ & $-4.771^{* * *}$ \\
\hline Jet Fuel - Brent (1) & Apr 2008 & $-4.147^{* * *}$ & $-2.656^{*}$ & $-3.624 * * *$ & $-2.591 * * *$ & $-4.387^{* * *}$ & $-2.841^{*}$ \\
\hline Crack Spread (2) & Mar 1995 & $-3.880^{* *}$ & $-3.860^{* * *}$ & $-3.435^{* *}$ & $-2.903^{* * *}$ & $-4.137 * * *$ & $-4.146^{* * *}$ \\
\hline
\end{tabular}

Notes: $\mathrm{C}$ and $\mathrm{T}$ stand for constant and trend, respectively. One, two and three stars demonstrate the rejection of the null hypothesis of unit-root at $90 \%, 95 \%$ and $99 \%$ confidence, respectively. Numbers in the parenthesis show the optimal lag-order chosen by employing several criterion including Final Prediction Error (FPE), Akaike Information Criterion (AIC), Hannan-Quinn Information Criterion (HQIC) and Schwarz's Bayesian Information Criterion (SBIC). We do not observe contradictory results between different tests. All tests fail to reject the existence of unit root in the first four time series; whereas, the unit-root hypothesis is rejected for the last four series.

Table 6: Unit-Root Tests for After Break-Point.

\begin{tabular}{|l|l|c|c|c|c|c|c|}
\hline Time-Series & Break-Point & ADF & ADF & DF-GLS & DF-GLS & PP & PP \\
\hline & & C \& T & C & C \& T & C & C \& T & C \\
\hline Brent (1) & Mar 2012 & -1.576 & -2.028 & -1.464 & -0.684 & -1.273 & -1.867 \\
\hline NY Gasoline (1) & Apr 2012 & -2.202 & -2.255 & -2.132 & -1.306 & -1.742 & -2.013 \\
\hline Heating Oil (1) & Mar 2012 & -1.301 & -1.742 & -1.283 & -0.648 & -1.082 & -1.661 \\
\hline Jet Fuel (1) & Feb 2012 & -1.434 & -1.752 & -1.393 & -0.685 & -1.174 & -1.620 \\
\hline Gasoline - Brent (2) & Dec 1994 & $-6.487 * * *$ & $-5.452^{* * *}$ & $-6.447^{* * *}$ & $-4.041^{* * *}$ & $-7.679 * * *$ & $-6.645^{* * *}$ \\
\hline Heating Oil - Brent (0) & Apr 1995 & $-4.843^{* * *}$ & $-3.807 * * *$ & $-4.602^{* * *}$ & $-2.112^{* *}$ & $-4.843^{* * *}$ & $-3.807^{* * *}$ \\
\hline Jet Fuel - Brent (1) & Apr 2008 & $-3.318^{*}$ & $-3.510^{* * *}$ & -1.452 & -0.544 & $-4.166^{* * *}$ & $-4.265^{* * *}$ \\
\hline Crack Spread (2) & Mar 1995 & $-6.062^{* * *}$ & $-4.229 * * *$ & $-6.008^{* * *}$ & $-2.875^{* * *}$ & $-7.627 * * *$ & $-5.457^{* * *}$ \\
\hline
\end{tabular}

Notes: $\mathrm{C}$ and $\mathrm{T}$ stand for constant and trend, respectively. One, two and three stars demonstrate the rejection of the null hypothesis of unit-root at $90 \%, 95 \%$ and $99 \%$ confidence, respectively. Numbers in the parenthesis show the optimal lag-order chosen by employing several criterion including Final Prediction Error (FPE), Akaike Information Criterion (AIC), Hannan-Quinn Information Criterion (HQIC) and Schwarz's Bayesian Information Criterion (SBIC). We do not observe contradictory results between different tests. All tests fail to reject the existence of unit root in the first four time series; whereas, the unit-root hypothesis is rejected for the last four series.

explain why low-cost Persian Gulf countries such as Iran and Saudi Arabia focus more on building crude oil extraction than refinery capacity.

Empirical Result 3 Refining margins are mean-reverting; whereas, crude oil prices contain a unit root. Based on the estimated values reported in Table 8, this is in support of the Theoretical Implication 2.

Empirical Result 4 There are structural breaks in the unit-root tests of crude oil and refining margins. However, the behavior of sub-samples before and after the break are broadly similar to each other.

Empirical Result 5 There relative volatility of the downstream fund is almost one order of magnitude smaller than of the upstream fund. Consistent with the Implication 2 of the theoretical model, this fact supports a risk-hedging view of the downstream investment. 
Table 7: Calibrated Processes

\begin{tabular}{|c|c|c|}
\hline \multicolumn{1}{c|}{ Entity } & $\frac{d P}{P}=\mu_{P} d t+\sigma_{P} d W$ & $\mu_{P}=0.006, \sigma_{P}=0.09$ \\
\hline Crude Oil Price & $d C=\mu_{C}(\bar{C}-C) d t+\sigma_{C} d W$ & $\bar{C}=\$ 4.32, \mu_{C}=0.28, \sigma_{C}=2.58$ \\
\hline Refinery Margin & $\frac{P_{t}}{r-\mu}-\frac{\theta}{r}$ & $\theta=\$ 5, P_{t}=\$ 50$ \\
\hline Oil Revenue & $\frac{\mu_{C}}{r} \bar{C}+C_{t}$ \\
\hline Downstream Revenue & $\frac{r+\mu_{C}}{2}$ & $r=\frac{0.05}{12}, C_{t}=5$ \\
\hline
\end{tabular}

Table 8: Relative Volatility of Upstream (Crude Oil) and Downstream (Refining) Revenues

\begin{tabular}{|c|c|c|c|}
\hline Sector & Present Value & Volatility (s.t.d) & $\frac{\text { std }}{\text { mean }}$ \\
\hline Oil revenues & $1.34 \mathrm{e}+04$ & $1.44 \mathrm{e}+04$ & 1.07 \\
\hline Downstream revenues & 650.75 & 78.38 & 0.12 \\
\hline
\end{tabular}

\section{CONCLUSION}

In this paper, we first develop two stylized theoretical models to demonstrate some tradeoffs in investment in upstream and downstream. The empirical analysis suggests that though the refining margin is smaller - compared to the large profit margins of the crude oil sector -, its hedging value provides some rationale for vertical integration. Moreover, the expected present value of downstream revenues is more predictable than that of the upstream sector. Downstream investment may include some local spillovers and technology transfer features; however, it is also subject to political economy considerations, including empire building by government officials.

If an upstream firm faces substantial volatility in its core business but expects weakly correlated profits in the downstream business, then going downstream can serve as a hedge against the vagaries in the firm's profits. ${ }^{21}$ The hedging argument applies to all industries where the margins are imperfectly correlated with the oil price. Thus, not only refineries (as shown in details in the previous sections) but also energy-intensive sectors such as airlines and metal smelters may offer a hedge. Low energy input costs are good news for all such industries. Therefore, the downstream of the oil sector is not the only option to provide a hedge. Oil-producing countries can find several other industries, with zero or even negative correlation to the upstream sector, to diversify their export base.

Our theoretical and empirical analyses of downstream investment have focused on the hedging perspective. Thus, we had to abstract from many other important aspects of the real world. However, the arguments in favor and against downstream investments are potentially beyond the hedging value. We present a brief list of alternative perspectives and metrics as potential research questions to be examined by future research.

Strategic Use and Market guaranty The ownership of a refinery will provide a guaranteed market for the upstream producer's crude oil. Moreover, through a direct export of refined products

21. If the equity of firms are traded in the market firm-level hedging might be socially inefficient or redundant because the investors can always hedge their risk by diversifying their investment. 
(which is not part of OPEC's mandate), OPEC member states can use their domestic refinery capacity to under-report their oil production numbers. This aspect is related to a long-lasting debate on the strategic behavior of OPEC members in response to changing environmental conditions ([24], [21], [5])

Security of Supply and Sanctions One political objective for investing in a downstream industry is to be less exposed to sanctions. There are many examples of this: the most recent example is Qatar facing the risk of a naval blockade. Iran and Russia also want to have a sufficient supply of refined products if they were to face more severe international sanctions. Examples of the past include South Africa, which went so far as to produce gasoline from coal to counter sanctions against the former Apartheid regime. The argument for self-sufficiency in refined products, however, has a political nature. We only note that domestic supply need not deliver the refined product at the lowest price (in particular if delivered by a vertically integrated monopoly) nor the intended security of supply. In this paper, we abstract from analyzing such political risks and leave a rigorous analysis of it to future research.

Industrial Organization our work did not discuss the industrial organization implications of vertical integration for the global energy market ([44]). If OPEC members also control the downstream sector, they may consider using their market power differently (c.f., [13]). Future research can also explicitly model the impact of domestic refining capacity on the bargaining power and the behavior of OPEC member countries. Another related extension in this direction is to consider the effect of the downstream investment on the optimal extraction rate of individual countries and also the pricing policies of OPEC.

Optimal Investment Timing Optimal investment decisions in the upstream and downstream sectors (especially under uncertainty) can be more explicitly modeled. To keep the analysis tractable, we assume several parameters to be exogenous. However, a more detailed optimal investment policy may take into account factors such as mean-reversion in interest rates and building costs, technological development, and the dynamics of carbon taxes. For example, an episode of low-interest rates may encourage oil-producing countries to take advantage of low financing costs and to aggressively build new capacities in the downstream sector. Follow-Up research can study the relation between optimal investment in the downstream and the supply side of the capital markets.

\section{ACKNOWLEDGMENTS}

This work was sponsored by the Economic Research Forum (ERF) and has benefited from both financial and intellectual support. The contents and recommendations do not necessarily reflect ERF's views.

\section{REFERENCES}

Aïd, R., G. Chemla, A. Porchet, and N. Touzi (2011). "Hedging and vertical integration in electricity markets." Management Science 57(8): 1438-1452. https://doi.org/10.1287/mnsc.1110.1357.

Al-Monsef, M.A. (1998). "Vertical integration strategies of the national oil companies." The Developing Economies 36(2): 203-222. https://doi.org/10.1111/j.1746-1049.1998.tb00217.x.

Al-Obaidan, A.M. and G.W. Scully (1993). "The economic efficiency of backward vertical integration in the international petroleum refining industry" Applied Economics 25(12): 1529-1539. https://doi.org/10.1080/00036849300000157.

Alexander, C., M. Prokopczuk, and A. Sumawong (2013). "The (de) merits of minimum-variance hedging: Application to the crack spread.” Energy Economics 36: 698-707. https://doi.org/10.1016/j.eneco.2012.11.016. 
Alhajji, A.F. and D. Huettner (2000). "OPEC and world crude oil markets from 1973 to 1994: cartel, oligopoly, or competitive?” The Energy Journal 21(3): 31-60. https://doi.org/10.5547/ISSN0195-6574-EJ-Vol21-No3-2.

Alwang, J. and P.B. Siegel (1994). "Portfolio models and planning for export diversification: Malawi, Tanzania and Zimbabwe.” The Journal of Development Studies 30(2): 405-422. https://doi.org/10.1080/00220389408422321.

Arrau, P. and S. Claessens (1992). Commodity stabilization funds volume 835 World Bank Publications.

Barrera-Rey, F. (1995). The effects of vertical integration on oil company performance Citeseer.

Beland, L.-P. and R. Tiagi (2009). Economic Freedom and the "Resource Curse": An Empirical Analysis Fraser Institute.

Bertinelli, L., A. Heinen, and E. Strobl (2009). "Export diversification and price uncertainty in developing countries: A portfolio theory approach." Available at SSRN 1327928. https://doi.org/10.2139/ssrn.1327928.

Böhringer, C., K.E. Rosendahl, and J. Schneider (2014). "Unilateral climate policy: can OPEC resolve the leakage problem?" The Energy Journal : 79-100. https://doi.org/10.2139/ssrn.2242240.

Borensztein, E., O. Jeanne, and D. Sandri (2013). "Macro-hedging for commodity exporters." Journal of Development Economics 101: 105-116. https://doi.org/10.1016/j.jdeveco.2012.08.005.

Buehler, S. and A. Schmutzler (2008). "Intimidating competitors: endogenous vertical integration and downstream investment in successive oligopoly.” International Journal of Industrial Organization 26(1): 247-265. https://doi.org/10.1016/j. ijindorg.2006.11.005.

Cabrales, A. and E. Hauk (2011). "The quality of political institutions and the curse of natural resources." The Economic Journal 121(551): 58-88. https://doi.org/10.1111/j.1468-0297.2010.02390.x.

Carlton, D. W. (1979). "Vertical integration in competitive markets under uncertainty." The Journal of Industrial Economics 27(3): 189-209. https://doi.org/10.2307/2098317.

Cherif, R. and F. Hasanov (2013). “Oil exporters' dilemma: How much to save and how much to invest.” World Development 52: 120-131. https://doi.org/10.1016/j.worlddev.2013.06.006.

Choi, K. and S. Hammoudeh (2009). "Long memory in oil and refined products markets." The Energy Journal 30(2): 97. https://doi.org/10.5547/ISSN0195-6574-EJ-Vol30-No2-5.

Devlin, J. and S. Titman (2004). "Managing oil price risk in developing countries.” The World Bank Research Observer 19(1): 119-139. https://doi.org/10.1093/wbro/lkh015.

Dixit, A. K. (1993). The art of smooth pasting volume 55 Taylor \& Francis.

Frankel, J.A. (2010). “The natural resource curse: a survey.” Technical report National Bureau of Economic Research. https:// doi.org/10.3386/w15836.

Gately, D. (1995). "Strategies for OPEC's pricing and output decisions.” The Energy Journal 16(3): 1-38. https://doi. org/10.5547/ISSN0195-6574-EJ-Vol16-No3-1.

Ghoddusi, H., M. Nili, and M. Rastad (2017). “On quota violations of OPEC members" Energy Economics 68: 410-422. https://doi.org/10.1016/j.eneco.2017.10.016.

Ghoddusi, H., S. Titman, and S. Tompaidis (2018). "Profit Dynamics in Commodity Processing Firms." Working Paper .

Griffin, J.M. and L.M. Vielhaber (1994). “OPEC production: the missing link.” The Energy Journal 15(SI): 115-132. https:// doi.org/10.5547/ISSN0195-6574-EJ-Vol15-NoSI-7.

Herzer, D. and F. Nowak-Lehnmann D. (2006). "What does export diversification do for growth? An econometric analysis." Applied economics 38(15): 1825-1838. https://doi.org/10.1080/00036840500426983.

Holland, S.P. (2003). "Extraction capacity and the optimal order of extraction." Journal of Environmental Economics and Management 45(3): 569-588. https://doi.org/10.1016/S0095-0696(02)00026-8.

Johansson, D.J., C. Azar, K. Lindgren, and T.A. Persson (2009). "OPEC strategies and oil rent in a climate conscious world." The Energy Journal 30(3): 23-50. https://doi.org/10.5547/ISSN0195-6574-EJ-Vol30-No3-2.

Joskow, P.L. (2012). "Vertical integration." The Antitrust Bulletin 57(3): 545-586. https://doi.org/10.1177/ 0003603 X1205700303.

Kilian, L. (2017). "The Impact of the Fracking Boom on Arab Oil Producers." The Energy Journal 38(6). https://doi. org/10.5547/01956574.38.6.1kil.

Krane, J. (2015). "A refined approach: Saudi Arabia moves beyond crude.” Energy Policy 82: 99-104. https://doi. org/10.1016/j.enpol.2015.03.008.

Labys, W.C. and M.J. Lord (1990). "Portfolio optimisation and the design of Latin American export diversification policies." The Journal of Development Studies 26(2): 260-277. https://doi.org/10.1080/00220389008422151.

Laughton, D.G., J.S. Sagi, and M.R. Samis (2000). "Modern asset pricing and project evaluation in the energy industry." Journal of Energy Literature 6: 3-46.

Lawal, A.I., A.A. Babajide, T.I. Nwanji, and D. Eluyela (2018). “Are Oil Prices Mean Reverting? Evidence from Unit Root Tests with Sharp and Smooth Breaks.” International Journal of Energy Economics and Policy 8(6): 292-298. 
Léautier, T.-O. and J.-C. Rochet (2014). "On the strategic value of risk management.” International Journal of Industrial Organization 37: 153-169. https://doi.org/10.1016/j.ijindorg.2014.07.006.

Levin, R.C. (1981). "Vertical integration and profitability in the oil industry." Journal of Economic Behavior \& Organization 2(3): 215-235. https://doi.org/10.1016/0167-2681(81)90019-6.

Lieberman, M.B. (1991). "Determinants of vertical integration: An empirical test." in "Academy of Management Proceedings," volume 1991 Academy of Management 31-35. https://doi.org/10.5465/ambpp.1991.4976493.

Mabro, R. (2006). Oil in the 21st century: issues, challenges and opportunities. Oxford University Press, USA.

Maslyuk, S. and R. Smyth (2008). "Unit root properties of crude oil spot and futures prices." Energy Policy 36(7): 25912600. https://doi.org/10.1016/j.enpol.2008.03.018.

Massol, O. and A. Banal-Estañol (2014). "Export diversification through resource-based industrialization: The case of natural gas." European Journal of Operational Research 237(3): 1067-1082. https://doi.org/10.1016/j.ejor.2014.02.043.

McLean, J.G. and R.W. Haigh (1954). The growth of integrated oil companies. Division of Research, Graduate School of Business Administration, Harvard University.

Merener, N. and M.E. Steglich (2018). "Output value risk for commodity producers: The uncertain benefits of diversification.” World Development 101: 322-333. https://doi.org/10.1016/j.worlddev.2017.05.039.

Norton, S.W. (1993). "Vertical integration and systematic risk: Oil refining revisited." Journal of Institutional and Theoretical Economics (JITE)/Zeitschrift für die gesamte Staatswissenschaft 149(4): 656-669.

Ross, M.L. (1999). “The political economy of the resource curse.” World politics 51(2): 297-322. https://doi.org/10.1017/ S0043887100008200.

Steele, H. and G. Daly (1981). "Vertical divestiture of the US oil industry and US-OPEC relations." Energy Economics 3(1): 43-56. https://doi.org/10.1016/0140-9883(81)90006-2.

Sukcharoen, K. and D.J. Leatham (2017). "Hedging downside risk of oil refineries: A vine copula approach.” Energy Economics 66: 493-507. https://doi.org/10.1016/j.eneco.2017.07.012.

Suzuki, A., L.S. Jarvis, and R.J. Sexton (2011). "Partial vertical integration, risk shifting, and product rejection in the highvalue export supply chain: The Ghana pineapple sector." World Development 39(9): 1611-1623. https://doi.org/10.1016/j. worlddev.2011.02.007.

Sykuta, M.E. (1996). "Futures trading and supply contracting in the oil refining industry." Journal of Corporate Finance 2(4): 317-334. https://doi.org/10.1016/0929-1199(96)00004-1.

Van der Ploeg, F. and S. Poelhekke (2009). "Volatility and the natural resource curse." Oxford economic papers 61(4): 727760. https://doi.org/10.1093/oep/gpp027.

Van der Ploeg, F. and A.J. Venables (2011). "Harnessing Windfall Revenues: Optimal Policies for Resource-Rich Developing Economies.” The Economic Journal 121(551): 1-30. https://doi.org/10.1111/j.1468-0297.2010.02411.x.

Varian, H.R. (1992). Microeconomic analysis. volume 2 Norton New York. 


\section{APPENDIX A: SUMMARY OF NOTATIONS}

Table 9: List of Variables and Notations

\begin{tabular}{|c|c|c|}
\hline Notation & Interpretation & Properties \\
\hline$U(X)$ & Utility of the social planner & Mean-variance specification \\
\hline$\gamma$ & Degree of risk-aversion & $\gamma=3$ is a typical assumption. \\
\hline$\omega$ & Degree of vertical integration & Control variable of the model \\
\hline$K_{U}$ & Level of upstream investment & Endogenous \\
\hline$K_{D}$ & Level of downstream investment & Endogenous \\
\hline$I_{1}\left(K_{U}\right)$ & Upstream investment cost function & $I_{1}^{\prime}>0, I_{1}^{\prime \prime}>0$ \\
\hline$I_{2}\left(K_{D}\right)$ & Downstream investment cost function & $I_{2}^{\prime}>0, I_{2}^{\prime \prime} 0$ \\
\hline $\bar{I}$ & Total investment budget & Exogenous \\
\hline$\theta$ & Cost of extraction & Assumed to be zero \\
\hline$\sigma_{R}$ & Variance of total revenues & \\
\hline$P$ & Spot price of crude oil & Random variable \\
\hline$C$ & Current level of refining margins & Random variable \\
\hline $\bar{P}$ & Baseline level of crude oil & Random variable \\
\hline$\sigma_{U}$ & Volatility of shocks to upstream & \\
\hline$\sigma_{D}$ & Volatility of shocks to downstream & \\
\hline$\sigma_{U, D}$ & $\begin{array}{l}\text { Covariance of shocks to upstream and } \\
\text { downstream revenues OR profit margins }\end{array}$ & - \\
\hline $\bar{C}$ & Long-run level of refining margins & $=\$ 4.32$ \\
\hline$\mu_{P}$ & Drift of crude oil process & $=0.006$ \\
\hline$\mu_{C}$ & Mean-reversion rate of refining margins & $=0.28$ \\
\hline$\sigma_{P}$ & Volatility of crude oil price process & 0.09 \\
\hline$\sigma_{C}$ & Volatility of refining margins process & $=2.52$ \\
\hline$\sigma_{V}$ & Volatility of crude oil revenue fund & $1.44 e 4$ \\
\hline$\sigma_{Y}$ & Volatility of refinery revenue fund & 78.38 \\
\hline$r$ & Discount rate & $=0.05$ per year \\
\hline$V$ & Present value of oil revenues & Closed-form solution \\
\hline Y & Present value of refining revenues & Closed-form solution \\
\hline$\varepsilon$ & Sensitivity of revenue value to spot values & Closed-form solution \\
\hline
\end{tabular}

\section{APPENDIX B: PROOF OF PROPOSITION 3.1}

For given levels of $K_{U}$ and $K_{D}$ the total revenue $R$ of the country is given by:

$$
R=\underbrace{[P-\theta] K_{U}}_{\text {Upstream Revenue }}+\underbrace{K_{D} C}_{\text {Downstream Revenue }}=K_{U}[P-\theta+\omega C]
$$

The variance of the revenue process is given by:

$$
\sigma_{R}^{2}=K_{U}^{2} \sigma_{U}^{2}+K_{D}^{2} \sigma_{D}^{2}+2 K_{U} K_{D} \operatorname{Cov}\left(\varepsilon_{C}, \varepsilon_{P}\right)
$$


Plugging the explicit values into the Lagrangian:

$$
\mathcal{L}=K_{U}[\bar{P}-\theta]+K_{D} \bar{C}-\frac{\gamma}{2} K_{U}^{2}\left[\sigma_{U}^{2}+\omega^{2} \sigma_{D}^{2}+2 \omega \operatorname{Cov}\left(\varepsilon_{C}, \varepsilon_{P}\right)\right]-\lambda\left[I_{1}+I_{2}-\bar{I}\right]
$$

The first order optimality conditions can be written as:

$$
\left\{\begin{array}{l}
\frac{\partial \mathcal{L}}{\partial K_{U}}=0 \Rightarrow[\bar{P}-\theta]-2 \gamma\left[K_{U} \sigma_{U}^{2}+K_{D} \sigma_{U, D}\right]=\lambda I_{1}^{\prime}\left(K_{U}\right) \\
\frac{\partial \mathcal{L}}{\partial K_{D}}=0 \Rightarrow \bar{C}-2 \gamma\left[K_{D} \sigma_{C}^{2}+K_{U} \sigma_{U, D}\right]=\lambda I_{2}^{\prime}\left(K_{D}\right)
\end{array}\right.
$$

The optimality conditions suggest that the marginal cost of investing an extra unit of capacity in each sector must be equal to the marginal benefit (i.e., sales price) corrected for the disutility of risk.

While a risk-neutral planner (i.e., when $\gamma=0$ ) will most likely choose a corner solution, a risk-averse planner will always choose an interior solution. If the social planner is risk-neutral or if both crude oil and refining margins are deterministic, the optimal conditions simplify to $\frac{\bar{P}-\theta}{\bar{C}}=\frac{I_{1}^{\prime}\left(K_{U}\right)}{I_{2}^{\prime}\left(K_{D}\right)}$. In this case, the optimal degree of vertical integration will be determined by pure return on investment (ROI) considerations. If the convexity of investment function is sufficiently weak (i.e., the investment cost is near-linear), this first-order condition (FOC) will likely result in a corner solution in which the investment will be allocated to the sector with the highest ROI (most likely the upstream sector for OPEC countries).

However, once the risk-aversion is introduced, the hedging value of diversification through downstream investment will be added to optimally conditions of the investment, as shown in Proposition 3.1.

\section{APPENDIX C: DYNAMICS OF DOWNSTREAM FUND}

The dynamics of the downstream value can be written as:

$$
\begin{aligned}
& d \mathrm{Y}=\mu_{C}\left(\frac{\bar{C}}{r}-Y_{t}\right)+\frac{\sigma}{r+\mu_{C}} d W_{C} \\
& Y_{t}=\frac{\bar{C}}{r}-\frac{\bar{C}}{r+\mu_{P}}+\frac{C_{t}}{r+\mu_{C}}=\frac{\frac{\mu_{C}}{r} \bar{C}+C_{t}}{r+\mu_{C}} \Rightarrow d V=\frac{d C_{t}}{r+\mu_{C}} \Rightarrow \frac{d V}{d C}=\frac{1}{r+\mu_{P}}
\end{aligned}
$$

The value is a function of the weighted sum of current and long-run crack spreads:

$$
\xi_{\text {Refinery Revenue }}=\frac{d V}{d C} \frac{C}{V}=\frac{1}{\left(r+\mu_{C}\right)} \frac{\left(r+\mu_{C}\right) C_{t}}{\frac{\mu_{C}}{r} \bar{C}+C_{t}}=\frac{C_{t}}{\frac{\mu_{C}}{r} \bar{C}+C_{t}}
$$

Since $\bar{C}>0$ the denominator is always larger than the numerator and as a result $0<\xi_{\text {Mean-reverting }}<1$. When $\mu_{C} \rightarrow 0$ (i.e. random walk) the effect of $\bar{P}$ vanishes and $\xi \rightarrow 1$. On the other end, when $\mu_{P} \rightarrow \infty$ (i.e. i.i.d distribution of prices) $\xi \rightarrow 0$. The limiting case of the independently and identically distributed refining margins $\left(\mu_{P} \rightarrow \infty\right)$, which was discussed in the static model, suggests that the expected net present value of refining profits will be a constant number despite the fact that each period's margin can be very volatile! 
We also see that a higher discount rate and a lower mean-reversion rate increase the sensitivity of the revenue value to the transient fluctuations of refining margins. When the $\mu_{C}>r$ condition holds, the weight of the long-run refining margins is bigger, and when $\mu_{C}<r$ the weight of current margins dominates. One can easily see that a smaller $\mu_{C}$ or a larger $r$ dilute the impact of $\bar{C}$ compared to $C_{t}$.

\section{APPENDIX D: PROOFS OF THEORETICAL IMPLICATIONS}

The comparative static of a constrained optimization problem can be derived from applying the insights of the Envelope theorem to the Lagrangian problem. For a given level of $K_{U}$ and $K_{D}$, a total differentiation of the budget constraint suggests that at the margin, an extra unit of downstream investment causes a $\frac{I_{2}^{\prime}\left(K_{D}\right)}{I_{1}^{\prime}\left(K_{U}\right)}$ units reduction in the capacity of upstream. The country loses $\frac{I_{2}^{\prime}\left(K_{D}\right)}{I_{1}^{\prime}\left(K_{U}\right)}(P-C-\theta)$ units of revenue for each extra unit of capacity installed in the downstream. However, the utility may improve because of risk-reducing features of diversification.

The key driver of the result is that the variance of the revenues is convex in the level of capacity of the respective sector. A marginal reduction of upstream capacity reduces $2 K_{U} \sigma_{P}^{2}$ units of upstream risks and increases the other two terms by $2 K_{D}\left[\sigma_{C}^{2}+\sigma_{U, D}^{2}\right]$. If $K_{D}<<K_{U}$ (little capacity in the downstream) or if $\sigma_{D}<\sigma_{U}$ (lower relative volatility of refining margins), the total volatility is reduced.

\section{D.1 Effect of Covariance and Volatility (Implications 1 and 2)}

$$
\frac{\partial \omega}{\partial\left[\frac{\sigma_{U}}{\sigma_{D}}\right]}>0
$$

The term $\gamma K_{U}^{2} \sigma_{D} \sigma_{U} \sigma_{U, D}$ represents an additional hedging value when $\sigma_{U, D}$ is negative.

$$
\frac{\partial \omega}{\partial \sigma_{U, D}}<0
$$

\section{D.2 Effect of Crude Oil Price (Implication 3)}

This negative correlation is not only a statistical artifact, but in agreement with economic intuition if one considers increasing marginal cost of refining in a merit-order type model. ${ }^{22}$ If oil prices are high due to adverse supply shocks, demand for refined products, and also the capacity utilization of the refinery sector will be low (under the usual ceteris paribus clause). This lower capacity utilization will lower the crack spreads of refined products, as less efficient refinery units will not run, and the efficiency rent accruing to efficient units will be lower. Conversely, low oil prices caused by favorable supply shocks (e.g., post-2015 situation) trigger a high refined products demand and consequently higher refining margins.

$$
\frac{\partial \omega}{\partial[\bar{P}-\bar{C}]}<0
$$

22. A merit-order model suggests that the industry will use the most efficient production units first and then, as demand increases, will utilize less efficient production units. The price of the good will be determined by the production cost of the marginal producer, and some Ricardian rent will accrue to all production units before the marginal one. 


\section{D.3 Effect of Extraction Costs (Implication 4)}

A high extraction cost, $\theta$, reduces the nominator of the left side of the FOC.

$$
\frac{\partial \omega}{\partial \theta}>0
$$

\section{D.4 Effect of Risk-Aversion (Implication 5)}

Under the realistic assumption of $\bar{P}>\bar{C}$ (see Table 1), a lower risk-aversion parameter shifts the optimal portfolio of investment toward the high-return sector.

$$
\frac{\partial \omega}{\partial \gamma}>0
$$

\section{D.5 Source of Crude Oil Price Shocks (Implication 6)}

A key parameter of the model is $\sigma_{U, D}$, the correlation between movements of crude oil prices and refining margins. To open up the black box of $\sigma_{U, D}$ Ghoddusi et al. (2018) provide a structural model of the refining margins dynamics. Their results show that the correlation of crude oil prices and crack spreads can be negative or positive, depending on the source of crude oil price shocks. If crude oil prices are driven down by favorable supply shocks (i.e., a shift of the supply curve to the left), crack spreads and crude oil prices move in opposite directions. Whereas, when the crude oil price is driven by demand shocks (i.e., the shift of the demand curve to the right/left), crack spreads and crude oil prices move in the same direction. We discuss two examples of sources of supply and demand shocks.

Shale Revolution The refinery sector will provide better hedging for their economy if the oil price is low because of a positive supply shock such as shale revolution or OPEC's decision not to cut production; a chief example of it is the 2014-2017 episode (Kilian, 2017).

The model captures the effect of the shale revolution through two major parameters: 1) a reduced $\bar{P}, 2$ ) a more negative $\sigma_{U, D}$. As shown in Appendix D, both effects increase the incentive to invest in the downstream.

Climate Change On the other hand, if the oil price is low due to the global recession and low demand, the refinery margins would also be low, and hedging will not be very effective. Climate change concerns and their impact on OPEC members' production is one of such demand factors (Böhringer et al., 2014; Johansson et al., 2009).

The model captures the effect of the climate through three major parameters: 1) a reduced $\bar{P}, 2$ ) a reduced $\bar{C}$, and 3) a more positive $\sigma_{U, D}$. As shown in $\mathrm{D}$, the first and the third effect will increase the incentive to invest in the downstream. However, the second effect will reduce such incentives. Thus, the net effect is ambiguous and depends on the magnitude of individual effects.

The overall decision depends on the historical magnitude of demand and supply shocks. 
Table 10: Effect of Crude Oil Shocks on Vertical Integration.

\begin{tabular}{|l|l|l|}
\hline Source of Shock & $\begin{array}{l}\text { Correlation of Crude Oil Prices and } \\
\text { Refining Margins }\end{array}$ & Implications for Vertical Integration \\
\hline $\begin{array}{l}\text { Shocks mainly to the supply of crude oil } \\
\text { (e.g. shale technology) }\end{array}$ & Negative & Larger degree of vertical integration \\
\hline $\begin{array}{l}\text { Shocks mainly to the demand for refined } \\
\text { products (e.g. climate change) }\end{array}$ & Positive & Smaller degree of vertical integration \\
\hline
\end{tabular}

Notes: The table suggests that vertical integration is more attractive when the source of threat is from the supply side (e.g. shale) than the demand (e.g. climate change).

\section{APPENDIX E: CAPITAL COSTS OF UPSTREAM AND DOWNSTREAM}

Upstream investment costs depend on the quality of the field and reservoir; moreover, the refinery's unit investment cost is a function of the complexity of the refining process. Thus, we do not claim to provide a precise number. However, by examining the existing data, we note that the estimated per barrel investment cost in the most efficient oil-producing countries (e.g., Iran) is still larger than a per barrel average refinery.

Upstream Capital Costs To evaluate investment costs in the upstream, we refer to an article in The Wall Street Journal ${ }^{23}$ which provides a range of capital cost estimates per barrel of crude oil. The lowest capital cost belongs to efficient OPEC members (such as Saudi Arabia and Iran), with less than $5 \$ / \mathrm{b}$ capital cost. For high-cost producers such as the U.S. and Brazil, the capital cost rises to $20 \$ / b$. Thus, one can assume that the per barrel upstream capital costs vary in the range of $5 \$ / b$ to $20 \$ / \mathrm{b}$.

Refinery Capital Costs The average capital cost for a $50000 \mathrm{~b} / \mathrm{d}$ refinery is estimated to be $20,000 * 50,000=1 e 9$ or one billion U.S. dollars. ${ }^{24}$ Assuming a 5\% cost of capital, this translates to 50 million USD annual capital cost. The refinery produces 17.5 million barrels per day. Thus, the average per barrel capital cost is $\frac{50,000,000}{17,500,000}=2.85 \$ / \mathrm{b}$. 